aggregated into a dichotomous total thumb base involvement score (0-1 in both joints vs $\geq 2$ in at least one joint).

Results: 85 out of 202 patients ( $84 \%$ women, mean age 60.1 years) reported pain on palpation in the thumb base. Synovitis was seen in both thumb base joints (CMC1 42\%, STT 37\%), although prevalence of grade 2-3 synovitis was low in both the CMC1 (16\%) and STT (14\%). BMLs were present in CMC1 and STT in 54 and $53 \%$, respectively, with 18 and $21 \%$ having a sum score of $2-3$, and 16 and $7 \%$ a sum score $\geq 4$. In absence of radiographic osteophytes, presence of synovitis or BMLs in either thumb base joint was not statistically significantly associated with thumb base tenderness (ORs 1.9 [95\% $\mathrm{Cl} 0.6-6.4]$ and 1.5 [0.5-4.3], respectively). However, in absence of synovitis or BMLs, radiographic osteophytes and pain were associated, with increasing ORs when MRI lesions were additionally present (Table). Similar results were found for self-reported thumb base pain (not shown)

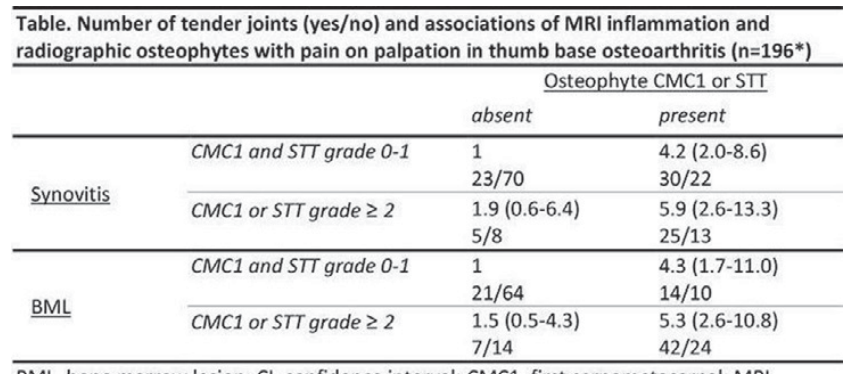

$\mathrm{BML}$, bone marrow lesion; $\mathrm{Cl}$, confidence interval; $\mathrm{CMC1}$, first carpometacarpal; MRI, magnetic resonance imaging; OR, odds ratio; STT, scaphotrapeziotrapezoid.

${ }^{*} n=196$ patients with available radiographs and evaluable MRI for synovitis and BMLs.

Conclusions: Synovitis and BMLs are present in the thumb base, although severe MRI lesions were uncommon. Prevalence of synovitis was similar in the CMC1 and STT joints, although higher BML scores were more frequently seen in CMC1. Radiographic osteophytes seemed more important in predicting thumb base tenderness than MRI inflammation alone. Combined presence of radiographic osteophytes and $M R I$ lesions had a small additive effect. These findings are in contrast to results from IP OA studies, supporting thumb base $\mathrm{OA}$ as a distinct hand $\mathrm{OA}$ subset. It might also explain why trials investigating intra-articular corticosteroids in thumb base OA have led to equivocal results.

References:

[1] Kroon F, Conaghan P, Foltz V, et al. J Rheumatol 2017 (in press).

Disclosure of Interest: None declared

DOI: 10.1136/annrheumdis-2017-eular.2879

\section{SAT0513 FUNCTIONAL IMPAIRMENT RATHER THAN BURDEN OF CO-MORBIDITIES IS ASSOCIATED WITH A 5-YEAR CHANGE IN HEALTH STATE UTILITY IN HIP AND KNEE OSTEOARTHRITIS: RESULTS FROM THE KHOALA COHORT STUDY}

A.Y. Omorou ${ }^{1,2}$, H. Achit $^{2}$, M. Wieczorek ${ }^{1}$, B. Fautrel ${ }^{3}$, A.-C. Rat ${ }^{1}$, F. Guillemin ${ }^{1,2}$. ${ }^{1}$ Ea 4360 Apemac, University of Lorraine; ${ }^{2} \mathrm{CIC}-1433$ Clinical Epidemiology, CHRU Nancy, Nancy; ${ }^{3}$ UPMC Université Paris 6, Grc-Upmc 08 (Eemois), Sorbonne Universités, Paris, France

Background: Functional impairment of hip and knee osteoarthritis (OA) and associated co-morbidities can independently impact patient's health state utility (HSU), a useful indicator for valuing health in medico-economic studies.

Objectives: This study aimed to examine the respective influence of the evolution of functional impairment and of burden of co-morbidities on a 5-year change in HSU for patients with OA.

Methods: 548 patients (Mean age of 61.1 years, $66.6 \%$ of women and $68.1 \%$ with knee OA) from the KHOALA study with 5 years follow-up were included. Functional impairment, co-morbidities and HSU were measured annually using the WOMAC (0-100) [1], FCl (1-18) [2] and SF-6D (0-1) [3], respectively. First, baseline clinical patterns were identified using hierarchical clustering methods [4]. Then, the role of these patterns as determinants of 5-year change in HSU was analysed using hierarchical mixed models.

Results: Two clusters were identified: cluster 1 "Low functional impairment and few co-morbidities" (65.3\%) and cluster 2 "Severe functional impairment and many co-morbidities" (34.7\%). Compared to the cluster 1, the functional impairment of cluster 2 significantly decreased $(-14.5[-18.1 ;-10.92])$ at 5 year follow up, while the co-morbidity index significantly increased in the two clusters $(+0.18[-0.22$; 0.57]). The mean baseline HSU score was 0.66 ( 0.70 for cluster 1 and 0.59 for cluster 2). Compared to cluster 1, patients in cluster 2 had a significantly higher increased in 5-year HSU $\left(\beta=+0.0335\right.$ [0.0088; 0.0583]) $\left(R^{2}=21 \%\right)$. The difference of 5 -year change in HSU was no more significant when adjusted for change in functional impairment $(\beta=+0.0335 ; p=0.008$ vs. $-0.0153 ; p=0.30)\left(R^{2}=42 \%\right)$ while it remained significant when adjusted for change in co-morbidity index $(\beta=+0.0335$; $p=0.008$ vs. $+0.0386 ; p=0.002)\left(R^{2}=27 \%\right)$.

Conclusions: Cluster analysis showed that patients with severe functional impairment also had high rate of co-morbidities à baseline. The reduction of OA functional impairment is an important determinant of 5-year improvement of HSU while burden of co-morbidities was not associated with change in hip and knee $\mathrm{OA} \mathrm{HSU}$. This result highlights the importance of reducing functional impairment in clinical management of patients with hip and knee OA, and gives clues for interpretation of medico-economic analyses.

References:

[1] Bellamy N, Buchanan WW, Goldsmith $\mathrm{CH}$, Campbell J, Stitt LW. Validation study of WOMAC: a health status instrument for measuring clinically important patient relevant outcomes to antirheumatic drug therapy in patients with osteoarthritis of the hip or knee. J. Rheumatol. 1988;15:1833-40.

[2] Groll DL, To T, Bombardier C, Wright JG. The development of a comorbidity index with physical function as the outcome. J. Clin. Epidemiol. 2005;58:595602

[3] Brazier J, Usherwood T, Harper R, Thomas K. Deriving a preferencebased single index from the UK SF-36 Health Survey. J. Clin. Epidemiol. 1998:51:1115-28.

[4] Everitt BS. Unresolved Problems in Cluster Analysis. Biometrics. 1979;35:169.

Disclosure of Interest: None declared

DOI: 10.1136/annrheumdis-2017-eular.3796

\section{SAT0514 CAN IMMUNOPHENOTYPING OF SYNOVIAL FLUID CELLS HELP DISTINGUISH BETWEEN PATIENTS WITH OSTEOARTHRITIS?}

G. Gabcova ${ }^{1}$, G. Manukyan ${ }^{2}$, Z. Mikulkova ${ }^{1}$, E. Kriegová ${ }^{1}$, J. Gallo $^{3}$. ${ }^{1}$ Department of Immunology, Faculty of Medicine and Dentistry, Palacky University, Olomouc, Czech Republic; ${ }^{2}$ Group of Molecular and Cellular Immunology, Institute of Molecular Biology NAS RA, Yerevan, Armenia; ${ }^{3}$ Department of Orthopaedics, Palacky University, Teaching Hospital Olomouc, Olomouc, Czech Republic

Background: Osteoarthritis $(\mathrm{OA})$ is a leading cause of chronic pain and functional disability in elder people. It is not a homogeneous but diverse group of synovial joint diseases. This could stay behind the therapeutic inconsistency observed in clinical practice caused probably by different diseases and/or different stages of a single disease. The comprehensive immunophenotyping of immune cells and their cell counts in synovial fluid (SF) might therefore advance our understanding of a particular type/stage of OA. This could have diagnostic value as well as provide novel insights into the pathophysiology of OA.

Objectives: To characterize immune cells present in SFs from OA patients in different stages of a disease.

Methods: We performed immunophenotyping of SFs from 63 patients with $\mathrm{OA}$ and $10 \mathrm{SFs}$ from control patients (non-OA) without clinical/radiographic signs of $\mathrm{OA}$ using flow cytometry. We were able to characterize the following immune cells in the sampled SFs: T helper lymphocytes $\left(\mathrm{CD}^{+} / \mathrm{CD} 4^{+}\right), \mathrm{T}$ cytotoxic lymphocytes $\left(\mathrm{CD}^{+} / \mathrm{CD}^{+}\right)$, NK cells $\left(\mathrm{CD}^{-} / \mathrm{CD} 16^{+} / \mathrm{CD}^{+} 6^{+}\right)$, B lymphocytes $\left(\mathrm{CD} 19^{+}\right)$, $\mathrm{T}$ regulatory (Treg) cells $\left(\mathrm{CD}^{+} / \mathrm{CD}^{2} 5^{+} / \mathrm{CD} 127^{-}\right)$, mast

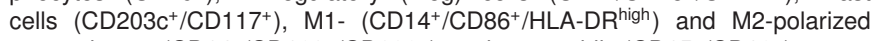
macrophages $\left(\mathrm{CD} 14^{+} / \mathrm{CD} 163^{+} / \mathrm{CD} 206^{+}\right)$, and neutrophils $\left(\mathrm{CD} 15^{+} / \mathrm{CD} 16^{+}\right)$.

Results: A comparison between $\mathrm{OA}$ and control (non-OA) SFs revealed phenotypic alterations mainly in T cells, NK cells, macrophages, and neutrophils. $\mathrm{T}$ cells were the predominant population in the SFs, with $\mathrm{CD}^{+}{ }^{+} \mathrm{T}$ lymphocytes being more prevalent than $\mathrm{CD}^{+} \mathrm{T}$ cells in $\mathrm{OA}$ (increased $\mathrm{CD} 4 / \mathrm{CD} 8$ ratio). The second largest cell population was macrophages. Despite the dominant mixed-polarized (M1-M2) macrophage subpopulations in both the studied groups, SFs from the OA patients displayed a tendency towards greater M1 activity comparing to the controls. A markedly increased percentage of neutrophils found in the OA group was associated with their activated state compared to the controls (increased CD11b). No difference was found in percentages of B, Treg and mast cells. Despite the similar numbers of NK cells in both the groups, the activation-associated marker CD69 was up-regulated in NK cells from the OA patients. Representative dot-plots (FCS-SSC) of inter-individual variability of the main immune cell populations in synovial fluids from osteoarthritic patients is shown in Figure 1.
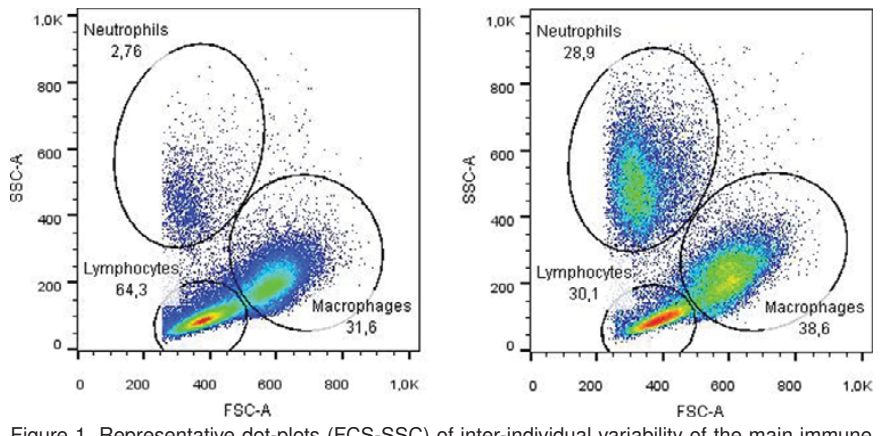

Figure 1. Representative dot-plots (FCS-SSC) of inter-individual variability of the main immune cell populations in synovial fluids from osteoarthritic patients.

Conclusions: We were able to distinguish between the OA cases and controls 
in terms of their immune cells profiles (i.e. their numbers, activation status etc.). Additionally, we were able to follow specific immune cell patterns inside the OA group. Our study further emphasized the role of immune cells in the pathogenesis of OA. In particular, the results provide evidence suggesting ongoing activation of innate immunity as well as a shift towards $T$ helper lymphocytes in fluids of the patients with OA. Our findings give a rational starting point to be addressed by the future research for clinically useful biomarkers associated with the OA development and progression.

Acknowledgements: Grant support: MZ CR VES16-31852A, MZ CR VES1527726A.

Disclosure of Interest: None declared

DOI: 10.1136/annrheumdis-2017-eular.4045

\section{SAT0515 SONOGRAPHIC AND CLINICAL EXAMINATION OF TENDON INVOLVEMENT IN HAND OSTEOARTHRITIS}

I. GessI, A. Vinatzer, G. Supp, A. Kerschbaumer, P. Studenic, M. Zauner, D. Aletaha, J. Smolen, P. Mandl. Dep. of Medicine 3, Div. of rheumatology, Medical University of Vienna, Vienna, Austria

Background: Persistent tenosynovitis and degenerative tendinitis is associated with pain and can lead to dysfunction and tendon damage. While tenosynovitis is a common finding in rheumatoid arthritis, data on tendon involvement in hand osteoarthritis (HOA) is clearly limited. The clinical assessment of tendons is difficult and not fully standardized, but muculoskeletal ultrasound (MSUS) has been used successfully in inflammatory rheumatic disease as a sensitive method to detect tenosynovitis, tendon damage and osteophytes.

Objectives: To characterize tendon involvement in hand osteoarthritis and compare ultrasound with clinical assessment.

Methods: In this cross-sectional observational study 34 patients with HOA underwent MSUS and clinical examination on the same day. Each flexor and extensor tendon of the hand was scored independently for tenosynovitis and tendon damage (presence/absence) respectively by an expert in MSUS, blinded to the results of the clinical examination. Additionally, osteophytes in the proximal and distal interphalangeal joints of the fingers were assessed. Clinical assessment of tendons for tendon involvement included volar or dorsal pain, crepitus and swelling involving the hand, wrist or forearm during active movement of the tendon against resistance according to the Birmingham consensus criteria, by assessors who were blinded to the results of the MSUS. Conventional radiographs (CR) of the hands were also acquired and evaluated by the Interphalangeal Osteoarthritis Radiographic Simplified score.

Results: The majority of patients $(30 / 34,88.2 \%)$ were female, with a mean age of $69.5 \pm 8.5$ years and a median of $10(9-22.5)$ years disease duration. Clinical examination revealed tendon involvement in $21(61.8 \%)$ patients with a median of 3 (range 1-14) affected tendons. In MSUS tenosynovitis was detected in $17 / 33$ patients $(51.5 \%)$ with a median of $1(1-4)$ tendon involved. Tendon damage was found in $8 / 33$ patients $(24.2 \%)$ with a median of $2(1-11)$ tendons involved. A total of $20 / 33(60.6 \%)$ patients exhibited sonographic signs of tendon involvement (tenosynovitis/tendon damage) with a median of $2(1-12)$ involved tendons. Tendon damage was found more often on the right hand $(p<0.05)$ while tenosynovitis did not significantly differ. Similarly, no significant difference between male and female patients was found. The extensor digitorum and the extensor carpi ulnaris tendons were the most commonly affected tendons under US. Tenosynovitis was found to be more prevalent among extensor tendons $(p<0.001)$, while tendon damage was demonstrated at a higher frequency in flexor tendons $(p<0.05)$ (Fig. 1). The agreement between MSUS and clinical examination was moderate on the patient level and poor on the level of individual tendons. Osteophytes were found in $96.8 \%$ patients using MSUS and in $100 \%$ of patients assessed using CR. Osteophytes detected on MSUS or CR showed good agreement $(p=0.01$, Cronbach's Alpha $=0.66)$.

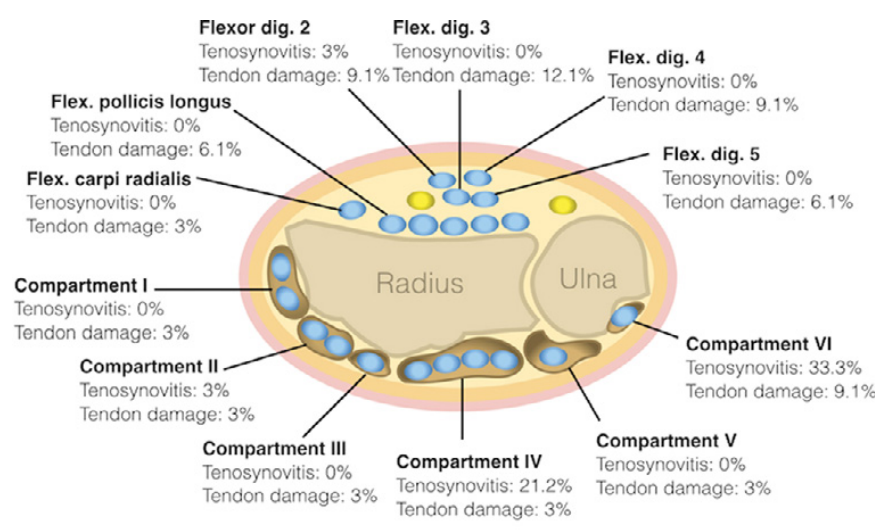

Fig.1 Distribution of tenosynovitis and tendon damage

Conclusions: The findings of our study reveal a high prevalence of tendon involvement in patients with hand OA. Sensitivity of MSUS in detecting tendon involvement coupled with the lack of agreement between clinical examination and MSUS on the level of individual tendons may suggest that while clinical examination is able to identify patients with overall tendon involvement, it does not allow the specific identification of involved tendons.

Disclosure of Interest: None declared

DOI: 10.1136/annrheumdis-2017-eular.5853

\section{SAT0516 INFLUENCE OF ETHNICITY ON CLINICAL PAIN IN PATIENTS WITH OSTEOARTHRITIS VERSUS RHEUMATOID ARTHRITIS: CONTRIBUTION OF LEVEL OF EDUCATION AND DEPRESSION}

I. Castrejon ${ }^{1}$, J. Chua ${ }^{1}$, J.A. Block ${ }^{1}$, L.A. Bradley ${ }^{2}$, Y. Yazici ${ }^{3}$, N. Shakoor ${ }^{1}$ ${ }^{1}$ Rheumatology, Rush University Medical Center, Chicago; ${ }^{2}$ Clinical Immunology and Rheumatology, University of Alabama, Birmingham; ${ }^{3}$ Rheumatology, NYU Hospital for Joint Diseases, New York, United States

Background: The experience of pain is characterized by inter-individual and group variability, with ethnicity being one potential contributing factor. In a systematic review, it was shown how African Americans (AA) demonstrated lower pain tolerance in experimental studies ${ }^{1}$. Pain is the most common and troubling symptom in patients with osteoarthritis (OA) -maybe reflecting damage- and in patients with rheumatoid arthritis (RA) -maybe reflecting synovitis- but other pain mechanisms are important.

Objectives: To investigate the influence of ethnicity on clinical pain and other outcomes and to identify potential predictors of higher scores for pain in AA and Hispanic patients with OA or RA seen in routine care.

Methods: As part of their clinic visit, all patients complete a multidimensional health assessment questionnaire (MDHAQ) at 2 academic sites. MDHAQ includes $0-10$ visual analogue scales (VAS) for pain, physical function, and a patient global evaluation (PATGL), and a depression score between others. The MDHAQ also include demographic data and patients "self-identify" their ethnicity. One random visit with complete questionnaire data for each $O A$ (ICD-9=715.0) and RA (ICD-9=714.0) patient from each site was included in this analysis. Comparison according to patients' self-reported ethnicity -White, African-American (AA) or Hispanics- were performed using ANOVA and chi-squared. Multiple regression models were performed to identify independent explanatory variables for clinical pain in AA and Hispanics groups versus White.

Results: The study included 402 OA patients and RA 373. There were no differences in age and gender between ethnicity groups in both diagnostic groups. Years of education were highest in the White followed by AA and then Hispanics in both $O A$ and RA. AA and Hispanics showed statistically significantly higher scores for pain (6.6 vs 5.3 in $O A, p<0.001 ; 5.7$ vs 4.4 in $R A, p<0.001)$ and lower physical function ( 3.2 vs 1.9 in $\mathrm{OA}, \mathrm{P}<0.001$; 3.2 vs 1.9 in $\mathrm{RA}, \mathrm{p}<0.001$ ) in comparison with Whites in both diagnostic groups. A lower level of education and a higher level of depression predicted greater pain on a MDHAQ in OA in separate models for AA and Hispanic patients and in RA in Hispanic patients (Table).

Table 1. Multiple regression models predicting clinical pain on a MDHAQ stratified by ethnicity

\begin{tabular}{|c|c|c|c|c|c|c|}
\hline \multirow[t]{2}{*}{ DV: MDHAQ-Pain (0-10) } & \multicolumn{3}{|c|}{ Osteoarthritis } & \multicolumn{3}{|c|}{ Rheumatoid Arthritis } \\
\hline & $\beta$ & $p$ & R squared & $\beta$ & $p$ & R squared \\
\hline \multicolumn{7}{|l|}{ Model 1} \\
\hline Age & -0.04 & 0.49 & $0.13^{*}$ & 0.08 & 0.25 & $0.10^{*}$ \\
\hline Sex & -0.07 & 0.21 & & 0.03 & 0.65 & \\
\hline African-Americans & 0.12 & 0.06 & & 0.04 & 0.94 & \\
\hline Education & -0.19 & 0.005 & & -0.09 & 0.19 & \\
\hline Depression & 0.19 & 0.002 & & 0.29 & $<0.001$ & \\
\hline \multicolumn{7}{|l|}{ Model 2} \\
\hline Age & -0.05 & 0.39 & $0.15^{\star}$ & 0.05 & 0.40 & $0.16^{\star}$ \\
\hline Sex & -0.12 & 0.07 & & 0.02 & 0.68 & \\
\hline Hispanic & 0.09 & 0.19 & & 0.03 & 0.63 & \\
\hline Education & -0.19 & 0.01 & & -0.19 & 0.01 & \\
\hline Depression & 0.21 & 0.002 & & 0.30 & $<0.001$ & \\
\hline
\end{tabular}

Conclusions: AA and Hispanic patients had higher level of pain than Whites, but these differences are mainly influenced by level of education and level of depression in OA and RA patients. These results support the biopsychosociocultural model of pain in which, ethnic group differences may be determined by multiple mechanisms including socio-cultural as education, and psychological as depression, in addition to biological pathways.

References:

[1] Rahim-Williams B, Riley JL, et al. Pain Med 2012, 13(4):522-540.

Disclosure of Interest: None declared

DOI: 10.1136/annrheumdis-2017-eular.3843 